\title{
Start-Up Business Camp TDA Wilayah Jakarta
}

\author{
Bambang Eko Samiono $^{1 *}$, Hanny Nurlatifah ${ }^{1}$

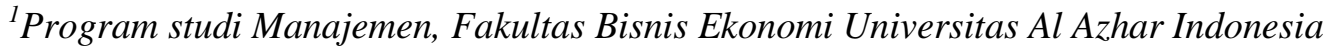 \\ Jalan Sisingamangaraja, Kompleks Masjid Agung Al Azhar, Kebayoran Baru, Jakarta Selatan 12110 \\ Email Penulis Korespondensi: be.samyono@uai.ac.id
}

\begin{abstract}
Tangan Di Atas Community is the largest entrepreneurial community in Indonesia, a place for new entrepreneurs to join in Indonesia. Some programs are mostly done to improve the capacity building of TDA members, but most of the programs are still not structured and segmented to a certain level. So this makes it difficult for novice business people to get training in the right package. It can also be seen that there are a lot of newbies entrepreneurs who follow various types of training repeatedly because they still do not understand how to apply the training material they get. The UAI community service team that has long worked with the TDA Internal Education Division collaborated as a contribution to provide solutions to the problems faced by partners by 1) Providing a Camp Workshop Series Program, 2) Provision of mentors by following their fields of ability provide a practical and systematic method and 3) Provide practical material of worksheets as a template for starting a business. The Start-Up Business Camp training was carried out in 4 sessions of 2 meetings with 10 novice business participants from South Jakarta and East Jakarta TDAs. At the end of the training, there was an evaluation of the level of satisfaction with the implementation of this training was $96 \%$.
\end{abstract}

\section{Keywords: Business, Entrepreneur, Mentoring, Start up, Training}

\begin{abstract}
Abstrak
Komunitas Bisnis Tangan Di Atas (TDA) adalah komunitas wirausaha terbesar di Indonesia, wadah bergabungnya para wirausahawan di Indonesia. Beberapa program banyak dilakukan untuk meningkatkan capacity building anggota TDA tersebut. Namun, sebagian besar program masih belum terstuktur dan tersegmen untuk level tertentu. Sehingga hal ini menyulitkan untuk pebisnis pemula untuk mendapatkan pelatihan dalam satu paket yang tepat. Selain itu, terlihat bahwa banyak sekali pebisnis pemula mengikuti berbagai macam pelatihan secara berulang karena masih belum paham bagaimana menerapkan materi pelatihan yang didapat. Tim pengabdian masyarakat yang telah lama bekerjasama dengan divisi edukasi Internal TDA Jakarta Selatan dan Jakarta Timur bekerjasama sebagai kontribusi untuk memberikan solusi terhadap permasalahan yang dihadapi mitra yaitu berupa 1) Memberikan Program Workshop series dalam bentuk Camp, 2) Penyediaan mentor yang sesuai dengan bidangnya yang mampu memberikan pembekalan secara praktis dan sistematis serta 3) Memberikan materi praktis berupa lembar kerja sebagai template untuk memulai bisnis sehingga bisa di gunakan secara praktis. Pelatihan Start Up Business Camp ini di jalankan dalam 4 sesi selama 2 kali pertemuan dengan 10 orang peserta bisnis pemula dari TDA Jaksel dan Jaktim. Di akhir pelatihan diperoleh evaluasi adanya tingkat kepuasan terhadap peaksanaan pelatihan ini sebesar $96 \%$.
\end{abstract}

Kata kunci: Bisnis, Wirausaha, Pendampingan, Start up, Pelatihan 


\section{PENDAhUluaN}

Komunitas Bisnis Tangan Di Atas (TDA) adalah komunitas wirausaha terbesar di Indonesia, wadah bergabungnya para wirausahawan Indonesia. Salah satu wilayah yang cukup eksis dengan kegiatannya adalah TDA Jakarta selatan dan Jakarta Timur. Sebagai komunitas bisnis start up kegiatan untuk meningkatkan kemampuan manajemen dan pengelolaan usaha anggotanya sangat esensial. (Kementrian Koperasi dan UKM RI, 2011). Saat ini program Kelompok Mentoring Bisnis (KMB) merupakan salah satu kegiatan untuk peningkatan Capacity Building tersebut.

Dengan kondisi demografi mayoritas member yang merupakan pengusaha start up dan merupakan konsen dari visi mereka untuk mencetak pengusaha terkemuka, TDA Jakarta Selatan dan Jakarta Timur mempunyai komitmen untuk meningkatkan kapabilitas anggotanya melalui berbagai program pemberdayaan dan pembekalan. Salah satu program major yang selalu dilakukan setiap tahun adalah program Kelompok Mentoring Bisnis (KMB). Disamping itu terdapat beberapa program pelatihan yang tidak terjadwal secara rutin dan berbeda beda temanya.

Tantangan yang mereka dapatkan dalam melakukan peningkatan Capacity Building ini adalah kurangnya team mentor internal yang bisa dilibatkan dalam program-program mereka. Terlebih beragamnya level bisnis para anggotanya membuat program pembekalan ini memerlukan sumberdaya pengajar yang cukup beragam pula sesuai dengan level bisnis mereka. Dari peserta sendiri tantangannya adalah banyaknya peserta dari level start-up merupakan karyawan yang masih bekerja dan memulai bisnis baru dalam tahap coba-coba. Tantangan dalam memberikan pembekalan terhadap mereka adalah bisa jadi mereka tidak langsung mempraktekkan ilmu yang ada. Sehingga penting bagi mereka untuk mendapatkan pembekalan berupa langkah-langkah praktis yang bisa mereka implementasikan dengan mudah begitu mereka siap menjalaninya dikemudian hari. (Szerb, 2010).

\section{Permasalahan Mitra}

Dari paparan diatas dapat disimpulkan beberapa hal yang menjadi permasalah bagi Mitra dalam menjalankan program KMB diantaranya:
1. Rendahnya kemampuan mengembangkan bisnis.

2. Terbatasnya mentor untuk memberikan pengajaran bagi anggota TDA.

\section{Solusi Permasalahan}

Menelaah permasalahan yang dihadapi oleh Mitra ini, maka tim pengabdian masyarakat yang telah lama bekerjasama dengan divisi edukasi Internal TDA Jakarta Selatan dan Jakarta Timur, bekerjasama untuk memberikan solusi terhadap permasalahan yang dihadapi mitra yaitu berupa (Gambar 1):

1. Memberikan Program Workshop series dalam bentuk Business Camp.

2. Penyediaan mentor yang sesuai dengan bidangnya

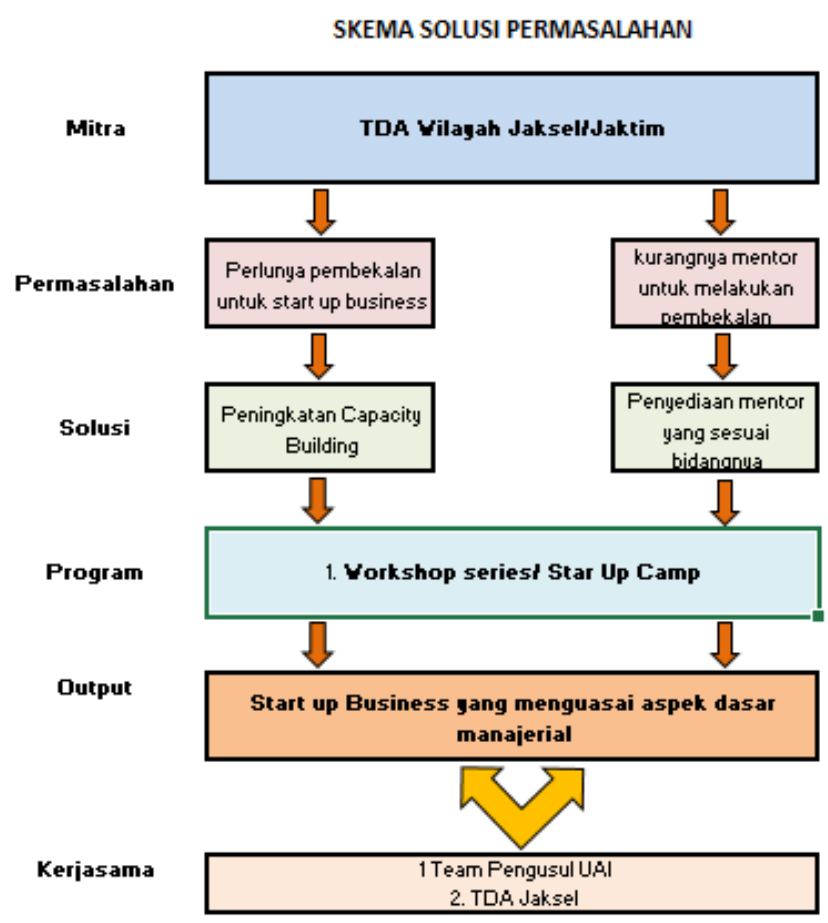

Gambar 1. Solusi Permasalahan

\section{METODE PELAKSANAAN}

\section{Tempat dan Waktu Pelaksanaan}

Pelaksanaan Start-Up Business Camp dilangsungkan di Lab Pasar Modal ruang 607 UAI tanggal Januari dan Maret 2020. Sementara waktu pelaksanaannya yang direncanakan dilakukan dalam 4 kali sesi dalam waktu 1 minggu sekali harus dipadatkan menjadi 4 kali sesi yang dilaksanakan 2 sesi per minggunya. Hal ini dikarenakan sulitnya mitra untuk berkomitmen bisa mengikuti Start-Up Business 
Camp secara penuh. Sementara untuk Jadwal mentoring dilakukan dengan system online menggunakan aplikasi google classroom.

\section{Pelaksanaan}

Berikut adalah tahap-tahap kegiatan pengabdian masyarakat yang akan dilakukan. Rencana kerja secara garis besar pelaksanaan dan gambaran prosedur kerja pengabdian masyarakat ini bisa dilihat pada Tabel 1 .

Tabel 1. Prosedur Kerja

\begin{tabular}{|c|c|c|c|}
\hline Kegiatan & Waktu & Luaran & $\begin{array}{c}\text { Produk yang } \\
\text { dihasilkan }\end{array}$ \\
\hline $\begin{array}{l}\text { Persiapan } \\
\text { Start up } \\
\text { Camp }\end{array}$ & $\begin{array}{c}1 \mathrm{x} \\
\text { perte } \\
\text { muan }\end{array}$ & $\begin{array}{l}\text { Team } \\
\text { merumuskan } \\
\text { materi } \\
\text { pelaksanaan dan } \\
\text { kriteria peserta } \\
\text { peserta }\end{array}$ & $\begin{array}{l}\text { - } \text { Silabi } \\
\text { Pengajaran } \\
\text { - } \text { Daftar } \\
\text { Peserta }\end{array}$ \\
\hline $\begin{array}{l}\text { Start up } \\
\text { Camp } 1 \\
\text { Materi } \\
\text { motivasi \& } \\
\text { goal setting }\end{array}$ & $\begin{array}{c}1 \mathrm{x} \\
\text { perte } \\
\text { muan }\end{array}$ & $\begin{array}{l}\text { Peserta } \\
\text { mendapatkan } \\
\text { pengetahuan, } \\
\text { pemahaman dan } \\
\text { Mentoring } \\
\text { mengenai } \\
\text { motivasi dan } \\
\text { goal setting (1) }\end{array}$ & $\begin{array}{l}\text { - Mengisi } \\
\text { lembar kerja } \\
\text { goal setting } \\
\text { - Mengisi } \\
\text { lembar kerja } \\
\text { time table }\end{array}$ \\
\hline $\begin{array}{l}\text { Start up } \\
\text { Camp } 2 \\
\text { Materi } \\
\text { Bisnis Model } \\
\text { Canvas }\end{array}$ & $\begin{array}{c}1 \mathrm{x} \\
\text { perte } \\
\text { muan }\end{array}$ & $\begin{array}{l}\text { Peserta } \\
\text { mendapatkan } \\
\text { pengetahuan, } \\
\text { pemahaman dan } \\
\text { Mentoring } \\
\text { mengenai bisnis } \\
\text { model canvas (2) }\end{array}$ & $\begin{array}{l}\text { - Lembar kerja } \\
\text { BMC terisi }\end{array}$ \\
\hline $\begin{array}{l}\text { Start up } \\
\text { Camp } 3 \\
\text { Marketing } \\
\text { Strategi }\end{array}$ & $\begin{array}{c}1 \mathrm{x} \\
\text { perte } \\
\text { muan }\end{array}$ & $\begin{array}{l}\text { Peserta } \\
\text { mendapatkan } \\
\text { pengetahuan, } \\
\text { pemahaman dan } \\
\text { Mentoring } \\
\text { mengenai } \\
\text { marketing } \\
\text { strategy (3) }\end{array}$ & $\begin{array}{l}\text { - Lembar kerja } \\
\text { marketing } \\
\text { strategi terisi }\end{array}$ \\
\hline $\begin{array}{l}\text { Start up } \\
\text { Camp } 4 \\
\text { Materi } \\
\text { Keuangan } \\
\text { \& evaluasi } \\
\text { penutupan }\end{array}$ & $\begin{array}{c}1 \mathrm{x} \\
\text { perte } \\
\text { muan }\end{array}$ & $\begin{array}{l}\text { Peserta } \\
\text { mendapatkan } \\
\text { pengetahuan, } \\
\text { pemahaman dan } \\
\text { Mentoring } \\
\text { mengenai } \\
\text { keuangan dan } \\
\text { evaluasi } \\
\text { penutupan (4) }\end{array}$ & $\begin{array}{l}\text { - Lembar kerja } \\
\text { keuangan } \\
\text { terisi } \\
\text { - Kompilasi } \\
\text { lembarr kerja }\end{array}$ \\
\hline $\begin{array}{l}\text { Survey } \\
\text { Kepuasan }\end{array}$ & & $\begin{array}{l}\text { Pendapat peserta } \\
\text { mengenai } \\
\text { perbaikan } \\
\text { program melalui } \\
\text { evaluasi }\end{array}$ & $\begin{array}{l}\text { - Kuisioner } \\
\text { kepuasan } \\
\text { - Hasil } \\
\text { kuisioner }\end{array}$ \\
\hline $\begin{array}{l}\text { Online } \\
\text { Mentoring }\end{array}$ & $\begin{array}{c}1 \\
\text { bulan }\end{array}$ & $\begin{array}{l}\text { Peserta } \\
\text { mendapatkan } \\
\text { mentoring } \\
\text { terhadap } \\
\text { implementasi } \\
\text { materi training } \\
\text { dalam bisnisnya }\end{array}$ & 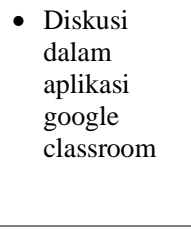 \\
\hline
\end{tabular}

\section{HASIL DAN PEMBAHASAN}

\section{a. Tahap Persiapan}

Persiapan Start Up Businass Camp dilakukan dalam 2 tahapan diantaranya adalah:

\section{1) Tahap Persiapan Peserta:}

Kegiatan ini direncanakan diikuti oleh 10 peserta yang merupakan member TDA Jakarta Selatan maupun Jakarta Timur. Perlu dipastikan bahwa semua peserta diharapkan mempunyai komitmen untuk bisa berkomitmen untuk mengikuti semua kegiatan yang dilaksanakan untuk mereka tanpa kecuali. Untuk tujuan ini team pengabdian masyarakat menetapkan 2 tahap pendaftaran.

\section{- Tahap Pendaftaran:}

Pada tahap ini team pengabdian masyarakat mempromosikan program start up business camp pada kanal kanal komunikasi pada TDA Jaktim maupun Jaksel. Dan untuk mempermudah pelaksanaan maka digunakan form pendaftaran online melalui google doc. Pada tahap pendaftaran ini di peroleh jumlah pendaftar 17 orang dalam waktu 3 hari sehingga diputuskan untuk menutup pendaftaran.

\section{- Tahap screening:}

Hal ini mutlak untuk dilakukan untuk mendapatkan komitmen peserta. Pada tahap ini peserta diberikan jadwal pelaksanaan besarta gambaran pelaksanaan secara detail disamping form konfirmasi online yang harus mereka isi. 10 peserta akhirnya di peroleh dan berhak untuk mengikuti program Strat Up Business Camp.

\section{2) Tahap Persiapan Materi}

Persiapan materi merupakan pelaksanaan kegiatan untuk menyusun modul yang komprehensip dan praktis dengan komponen utama berupa kertas kerja. Modul tersebut meliputi:

- Modul Motivasi Success Mindset + Lembar Kerja

- Modul Model bisnis + Lembar Kerja

- Modul Strategi Pemasaran+ Lembar Kerja

- Modul Strategi keuangan + Lembar Kerja 
Modul tersebut diatas diberikan kepada peserta berupa hard copy maupun Soft Copy. Lembar kerja merupakan tools template yang sangat praktis untuk mereka isi dan terapkan dalam implementasi bisnis mereka dan disesuakian dengan bahan ajar (lemhanas 2013)

\section{b. Tahap Pelaksanaan}

Pelaksanaan Start Up Businass Camp dilakukan dalam dua kali pelaksanaan yaitu pada Januari - Maret 2020. Masing masing materi berdurasi 2 jam dengan aktifitas paparan oleh mentor serta dilanjutkan dengan aktifitas latihan mengisi lembar kerja dan diskusi. Berikut daftar peserta selama 2 hari pelaksanaan Start Up Business Camp.

Tabel 2. Daftar Peserta

\begin{tabular}{|c|c|c|c|}
\hline $\begin{array}{l}\text { No } \\
\text { mor }\end{array}$ & Email Address & $\begin{array}{c}\text { Nama } \\
\text { Lengkap }\end{array}$ & Status \\
\hline 1 & $\begin{array}{l}\text { risa.bluesaphier@gma } \\
\text { il.com }\end{array}$ & $\begin{array}{l}\text { Eneke } \\
\text { Arisanti }\end{array}$ & $\begin{array}{l}\text { Pengusaha } \\
\text { Pemula }\end{array}$ \\
\hline 2 & $\begin{array}{l}\text { tbsuryamandala@gma } \\
\text { il.com }\end{array}$ & $\begin{array}{l}\text { Tubagus } \\
\text { Surya } \\
\text { Mandala }\end{array}$ & $\begin{array}{l}\text { Karyawan } \\
\text { swasta }\end{array}$ \\
\hline 3 & ooktieko@gmail.com & $\begin{array}{l}\text { Okti Eko } \\
\text { Nurati }\end{array}$ & $\begin{array}{l}\text { Karyawan } \\
\text { swasta }\end{array}$ \\
\hline 4 & $\begin{array}{l}\text { wati_arlinawati@yaho } \\
\text { o.com }\end{array}$ & Arlinawati & $\begin{array}{l}\text { Pengusaha } \\
\text { pemula }\end{array}$ \\
\hline 5 & $\begin{array}{l}\text { Ismawti.jkt@gmail.co } \\
\mathrm{m}\end{array}$ & Ismawati & $\begin{array}{l}\text { Pengusaha } \\
\text { pemula }\end{array}$ \\
\hline 6 & $\begin{array}{l}\text { dianadwiastuti99@gm } \\
\text { ail.com }\end{array}$ & $\begin{array}{l}\text { Diana Dwi } \\
\text { Astuti }\end{array}$ & $\begin{array}{l}\text { Pengusaha } \\
\text { pemula }\end{array}$ \\
\hline 7 & mazdono@yahoo.com & $\begin{array}{l}\text { Wahyu } \\
\text { Sadono }\end{array}$ & $\begin{array}{l}\text { Karyawan } \\
\text { swasta }\end{array}$ \\
\hline 8 & $\begin{array}{l}\text { feby.azrian@gmail.co } \\
\text { m }\end{array}$ & $\begin{array}{l}\text { Feby } \\
\text { Azrian }\end{array}$ & $\begin{array}{l}\text { Masih } \\
\text { menyiapkan } \\
\text { bisnis }\end{array}$ \\
\hline 9 & uppieaja@gmail.com & Uppie & $\begin{array}{l}\text { Pengusaha } \\
\text { pemula }\end{array}$ \\
\hline 10 & $\begin{array}{l}\text { melychilpo@gmail.co } \\
\text { m }\end{array}$ & Meliyani & $\begin{array}{l}\text { Pengusaha } \\
\text { pemula }\end{array}$ \\
\hline
\end{tabular}
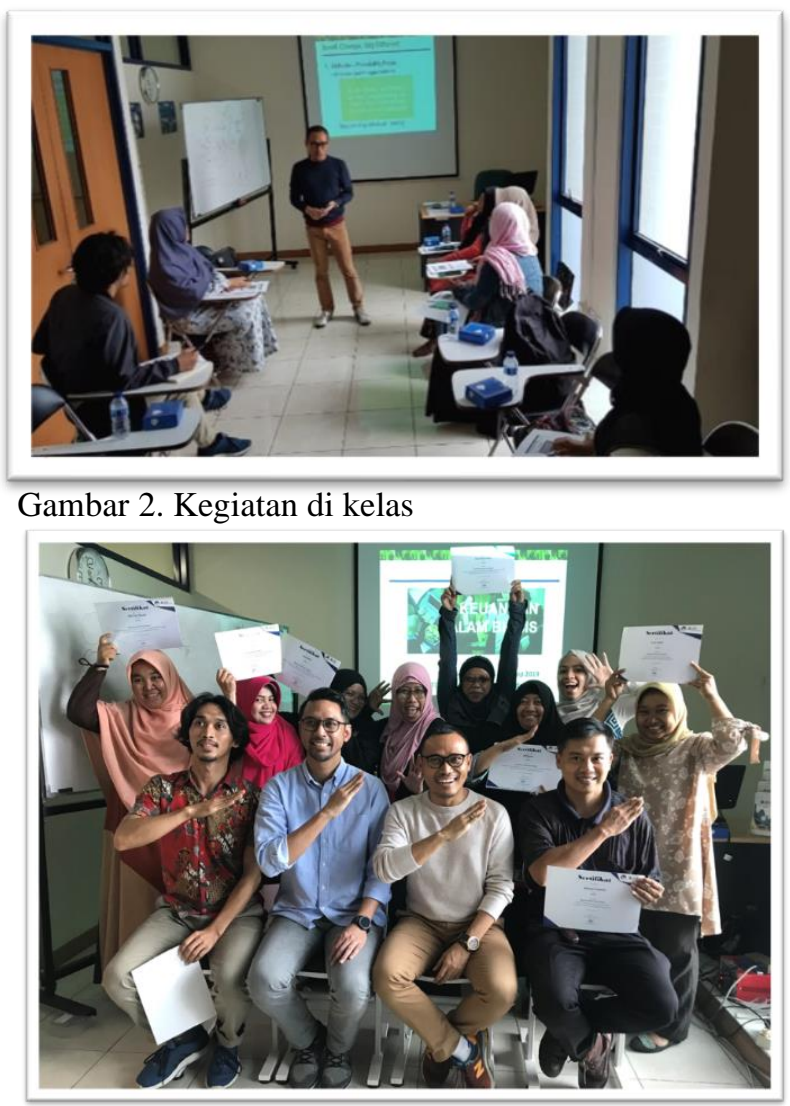

Gambar 3. Gambar Acara Penutupan

\section{c. Tahap Monitoring}

Mentoring dilakukan selama 1 bulan dengan menggunakan aplikasi google class room. Ketidak mungkinan melakukan monitoring secara offline dikarenakan keterbatasan anggaran yang ada sehingga team memutuskan untuk menggunakan google class room. Dalam aplikasi ini Pengajar dan Peserta bisa melakukan kegiatan pengajaran online berupa:

- Pendistribusian materi belajar

- Pemberian assignment

- Tanya jawab pertanyaan ataupun konsutasi

Dari monitoring di peroleh evaluasi 3 orang yang terlibat dalam konsultasi aktif bisnisnya. Sementara sisanya lebih banyak terlibat untuk memberikan saran dan pendapat terkait tanya jawab dalam konsultasi tersebut. 


\section{d. Tahap Evaluasi Program: (Survey Kepuasan)}

Diakhir sesi dibagikan kuisioner mengenai tingkat kepuasan dengan menggunakan metode Customer Satisfaction Index (CSI) dalan mengikuti program Start Up Business Camp ini. Evaluasi ini untuk mengukur kepuasan peserta dalam mengikuti program ini Pertanyaan tersebut mengenai:

- Pendapat mengenai program Start Up Business Camp ideal yang diinginkan

- Pendapat mengenai program Start Up Business Camp di UAI Dan hasilnya terpapar sebagai berikut:

- Hasil perhitungan Customer Satisfaction Index (CSI) pada program Start Up Business Camp di UAI sebesar: $96.0 \%$

- Tingkat kepuasan peserta cukup tinggi dimana terlihat gap yang ada antara harapan dan kenyataannya bernilai positif. Dimana berarti kenyataan mempunyai nilai lebih tinggi daripada harapan mereka. Nilai tertinggi ditunjukkan pada item fasilitas rungan khusus sebesar $(0,90)$ sementara terkecil pada kesesuian materi dengan level bisnis mereka dengan nilai $(0,00)$.

\section{SIMPULAN DAN SARAN}

Program Start Up Business Camp ini merupaka solusi yang tepat untuk memberikan peningkatan capacity building bagi anggota TDA Jaksel dan Jaktim yang berada pada level bisis pemula. Belum adanya program pelatihan yang terstruktur, terintegrasi dan terfokus pada satu level bisnis diatasi dengan memberikan program business camp yang mempunyai keunggulan antara pemberian materi yang praktis berupa metode lembar kerja materi motivasi, konsep bisnis, marketing serta keuangan. Lembar kerja ini berupa template yang akan bisa mereka praktekkan bila mereka siap untuk menjalankan bisnis.

Disamping itu pemberian mentor yang tepat yang bisa memadukan antara teori dan paktek sangat membantu peserta untuk mengatasi permasalahan dalam bisnisnya. Beberapa terobosan lain yang diupayakan dalam program ini adalah pemberian materi motivasi sehingga peserta bisa melihat perspektif bisnis dengan benar serta adanya mentoring online dengan menggunakan google class room. Pengukuran kepuasan terhadap business camp ini juga dilakukan dimana diperoleh tingkat kepuasan sebesar 96\% dimana mengindikasikan bahwa program ini termasuk berhasil.

Saran yang diberikan adalah metode Start-up business camp ini bisa diaplikasikan dan dijadwalkan secara rutin untuk anggota TDA wilayah. Keunikan materi dalam desain ini bisa menjembatani adanya kendala yang sebagian besar member TDA punyai yaitu:

1. Biasanya mereka tidak bisa langsung mengimplementasikan hasil pelatihan karena kebanyakan dari mereka masih dalam tahap coba-coba dan mempunyai pekerjaan tetap utama. Mereka akan mengimplementasikan setelah mereka siap.

2. Member TDA memerlukan modul yang praktis dan sistematis yang bisa menjadi panduan mereka bila satu saat akan menjalankan usaha.

\section{UCAPAN TERIMA KASIH}

Kami ucapkan terim akasih kepada tim Pengurus TDA Jaktim dan Jaksel serta Fakultas FEB atas keterlaksanaan program ini.

\section{DAFTAR PUSTAKA}

Kementerian Koperasi dan UKM RI. Laporan Kinerja 2011, Kebangkitan Koperasi dan UMNKM: Menuju Kesejahteraan Rakyat

Lemhannas RI. (2013). PPRA L. Modul BS Ketahanan Nasional.

Lemhannas RI. (2013). PPRA L. Bahan-bahan Ceramah Tajar BS. Lingkungan Strategis Kontemporer, SBS. Isu Global Kontemporer.

Acs, Zoltan J., Laszlo, Szerb. (2010). "The Global Entrepreneurship and Development Index (GEDI)", Paper to be presented at the Summer Conference 2010 on "Opening Up Innovation: Strategy, Organization, and Technology," Imperial College London Business School, June 16-18. 